\title{
Ultimate Capacity Analysis and Determination of the Position of Failure Surface for Uplift Piles
}

\author{
Qian Su, ${ }^{1}$ Xiaoxi Zhang, ${ }^{1}$ Pingbao Yin, ${ }^{2}$ and Wenhui Zhao ${ }^{1}$ \\ ${ }^{1}$ School of Civil Engineering, Southwest Jiaotong University, Chengdu, Sichuan 610031, China \\ ${ }^{2}$ School of Civil Engineering and Architecture, Changsha University of Science \& Technology, Changsha, Hunan 410076, China \\ Correspondence should be addressed to Xiaoxi Zhang; zhangxiaoxi2529@163.com
}

Received 4 July 2013; Revised 13 February 2014; Accepted 5 March 2014; Published 7 April 2014

Academic Editor: Pedro Ribeiro

Copyright (C) 2014 Qian Su et al. This is an open access article distributed under the Creative Commons Attribution License, which permits unrestricted use, distribution, and reproduction in any medium, provided the original work is properly cited.

\begin{abstract}
Ultimate capacity and failure surface position of uplift piles are dependent on soil parameters. In this paper, the horizontal slice method is used to discuss the relation among the ultimate uplift capacity, the failure surface position, and soil parameters with MohrCoulomb failure criterion. According to the limit equilibrium analysis, the ultimate uplift capacity is calculated by dividing soil around the pile into slices with considering the potential failure surface as a group of several sectional planes. Then the multivariate function used to calculate ultimate capacity is established and optimized by the sequential quadratic programming. Through the numerical calculation and comparison with the previous research, the results show that the method is reasonable and effective and can be used to determine the failure surface and the magnitude of the ultimate capacity of uplift piles.
\end{abstract}

\section{Introduction}

Uplift piles are commonly used as foundation systems for structures requiring uplift resistance such as high-rise structures and transmission lines. However, the problems of how to determine the position of failure surface and how to evaluate ultimate uplift capacity are difficult in the designing of the geotechnical engineering. The pile-soil interaction mechanism is not well understood, and very few papers are available to analyse the ultimate uplift capacity and failure mechanism.

So far, there are three main approaches for studying the uplift piles: laboratory model test, field test, and theoretic analysis. Deshmukh et al. [1] estimated the uplift capacity of pile anchors in cohesionless soil using Kotter's equation and assuming the cone frustum failure surface. Shelke et al. $[2,3]$ proposed to predict the ultimate uplift capacity of the single bent pile and pile group with a bent embedded in sand considering arching effect. Shanker et al. [4] presented a simple semiempirical model for predicting the uplift capacity of piles embedded in sand. But they are only applicable for sand and cohesionless soil. For clayey soil, Mohan and Chandra [5], Turner [6], and Sowa [7] reported the ultimate uplift capacity of vertical cast in situ concrete piles in clay subjected to axial uplifting force. Shin et al. [8] presented laboratory model test results for estimation of the ultimate uplift capacity of rigid metal piles embedded in a compacted near-saturated clayey soil.

In previous researches, line and curve failure surfaces were assumed; however, ultimate capacity and failure surface shape of the uplift piles influenced each other and they were dependent on soil parameters such as internal frictional angle, cohesion, pile-soil friction angle, and unit weight of the soil. In this paper, we study the uplift capacity and failure surface position with $c-\varphi$ soil using horizontal slice method. The $c-\varphi$ soil around uplift piles was divided into multiple slices, and the ultimate uplift capacity and failure surface were considered as the combination of multiple slices. It can be known that when the number of segments was infinite uplift capacity takes its accurate value. Based on the limit equilibrium approach, we analyzed the forces balance of the $c-\varphi$ soil. Then the multivariate function to calculate uplift capacity was established and optimized by the sequential quadratic programming. Lastly, we report net uplift capacity of the pile compared with previous researches.

\section{Load Transfer Mechanism of Uplift Pile}

The load transfer process and failure mechanism are shown in Figure 1. The relative displacement between the pile and 


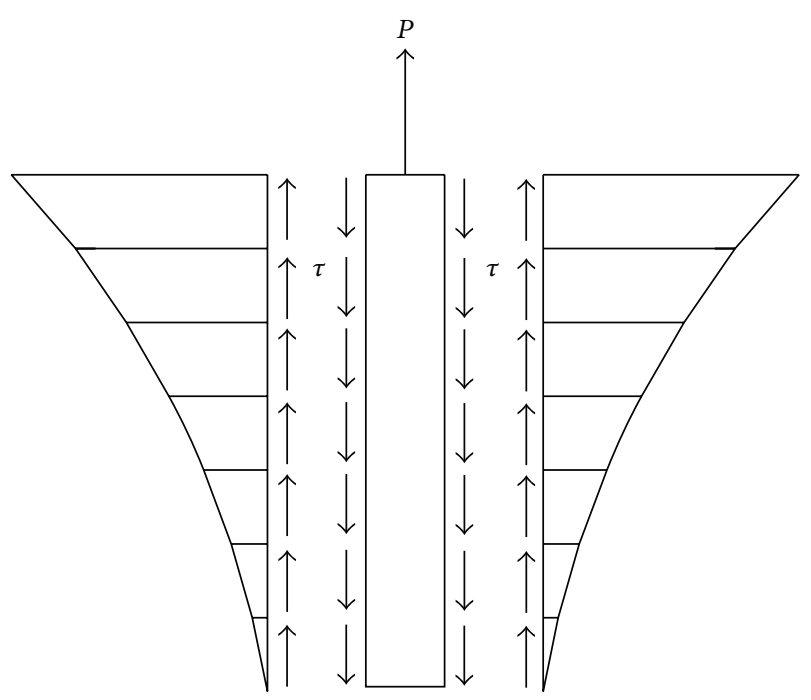

FIgURE 1: The load transfer mechanism of uplift pile.

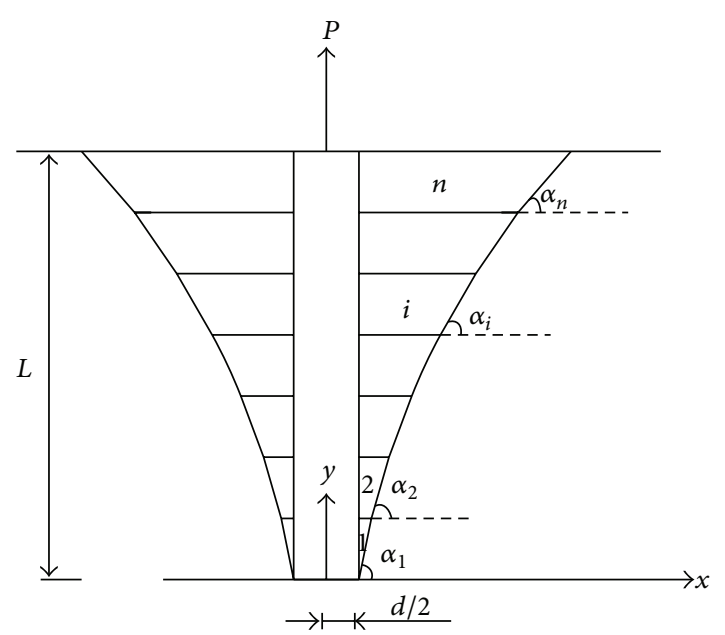

FIgURE 2: The model of the single pile under the uplift load.

the soil occurs as the pile is acted on by the uplift load, where the uplift load would be transferred to the soil by the shaft resistance. With the uplift load on the pile, the shaft resistance will increase fast. When it reaches a certain critical value, tensile-shear failure of soil will occur and then the pile and the soil will be extracted. In this case, the shaft resistance equals the net uplift capacity value.

\section{Theoretical Model}

The model of calculation for uplift capacity of single piles with $c-\varphi$ soil is shown in Figure 2. The failure surface of soil around the pile was usually considered as a straight line or curves, but, in fact, the shape and position of failure surface are unknown and are determined by some parameters. The $c-\varphi$ soil around the pile is divided into masses with considering the failure sliding surface as a group of several sectional planes; the angle between every sectional failure surface and horizontal plane is $\alpha_{i}$. If the number of sections is large enough, we can get

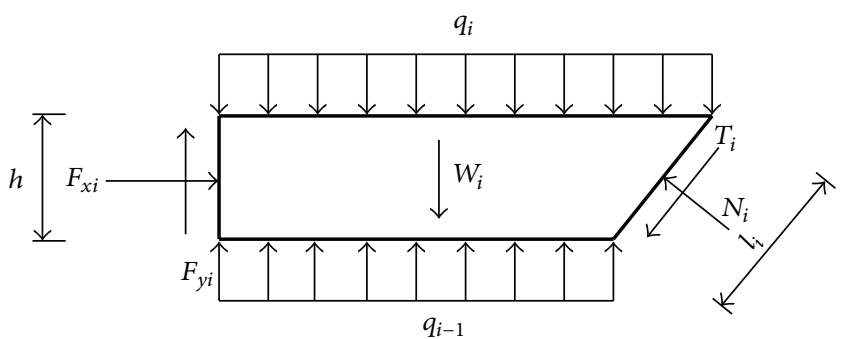

FIgURE 3: The calculation model of multiple slices.

smooth and continuous failure surface and the reasonable uplift capacity.

Figure 3 shows the plane calculation model of multiple masses with horizontal slice method. The following assumptions are also made: (1) backfill material obeys MohrCoulomb failure criterion. (2) The $c-\varphi$ soil is homogeneous and isotropic. (3) The failure surface is tangent to a point of tip of pile or the pile surface. (4) The horizontal interslices force is ignored.

During uplift of a vertical circular pile embedded in sand, an axisymmetric solid body of revolution of soil along with the pile is assumed to be initiated to move up along the resulting surface.

In the failure surface, the forces $R_{i}$ and $T_{i}$ are related as

$$
T_{i}=R_{i} \tan \varphi+c l_{i}
$$

where $l_{i}$ is the length of $i$ th sectional failure surface; $R_{i}$ is the normal force in the $i$ th sectional failure surface; $T_{i}$ is the tangential force in the $i$ th sectional failure surface. Consider

$$
l_{i}=\frac{h}{\sin \alpha_{i}}=\frac{H}{n} \frac{1}{\sin \alpha_{i}} .
$$

The equilibrium of forces in the horizontal direction for the $i$ th mass gives

$$
\begin{gathered}
\sum X=0, \\
\pi d F_{x i}=2 \pi\left(\frac{d}{2}+\frac{t_{i}+t_{i-1}}{2}\right)\left(T_{i} \cos \alpha_{i}+N_{i} \sin \alpha_{i}\right),
\end{gathered}
$$

where $t_{i}$ is the length of the $i$ th slice surface and the expression is as follows:

$$
t_{i}=\frac{1}{2} d+h \sum_{j=1}^{i} \cot \alpha_{j} .
$$

The equilibrium of forces in the vertical direction for the $i$ th mass gives

$$
\begin{gathered}
\sum Y=0 \\
\pi d F_{y i}=W_{i}+2 \pi\left(\frac{d}{2}+\frac{t_{i}+t_{i-1}}{2}\right)\left(T_{i} \sin \alpha_{i}-N_{i} \cos \alpha_{i}\right) \\
+\pi q_{i}\left[\left(\frac{d}{2}+t_{i}\right)^{2}-\left(\frac{d}{2}\right)^{2}\right] \\
-\pi q_{i-1}\left[\left(\frac{d}{2}+t_{i-1}\right)^{2}-\left(\frac{d}{2}\right)^{2}\right],
\end{gathered}
$$


where $q_{i}$ is soil pressure in the $i$ th slice and the expression is as follows:

$$
q_{i}=\gamma h(n-i)
$$

and $W_{i}$ is the weight of soil slice and the expression is as follows:

$$
W_{i}=\pi\left[\left(\frac{d}{2}+\frac{t_{i}-t_{i-1}}{2}\right)^{2}-\left(\frac{d}{2}\right)^{2}\right] h \gamma .
$$

The forces $F_{x i}$ and $F_{y i}$ and $P_{a}$ are related as

$$
\frac{F_{y i}}{\sin \delta}=\frac{F_{x i}}{\cos \delta} .
$$

Solving (11) and (13), the uplift pile frictional resistance can be expressed as

$$
\begin{aligned}
F_{y i}=\frac{1}{d}\left(A_{i} W_{i}+q_{i}\left[\left(\frac{d}{2}+t_{i}\right)^{2}-\left(\frac{d}{2}\right)^{2}\right] A_{i}\right. \\
\quad-q_{i-1}\left[\left(\frac{d}{2}+t_{i-1}\right)^{2}-\left(\frac{d}{2}\right)^{2}\right] A_{i} \\
\left.\quad+c l_{i}\left(A_{i} \sin \alpha_{i}-B_{i} \cos \alpha_{i}\right)\left(d+t_{i}+t_{i-1}\right)\right) \\
\times\left(A_{i}-B_{i} \cot \delta\right)^{-1} .
\end{aligned}
$$

The uplift capacity component can be reduced as

$$
P_{u}=\pi d \sum_{i=1}^{n} F_{y i}=f\left(\alpha_{1}, \alpha_{2}, \ldots, \alpha_{n}\right) .
$$

The uplift capacity of single piles is obtained by minimizing $P_{u}$ with respect to $\alpha_{i}$. To this end, the following set of equations has to be solved:

$$
\begin{gathered}
\frac{\partial P_{u}}{\partial \alpha_{1}}=0 \\
\frac{\partial P_{u}}{\partial \alpha_{2}}=0 \\
\vdots \\
\frac{\partial P_{u}}{\partial \alpha_{n}}=0 .
\end{gathered}
$$

Knowing the length of the single pile $(L)$, unit weight $(\gamma)$, cohesion $(c)$, internal friction angle $(\varphi)$ of soil, the pilesoil friction angle $(\delta)$, and the pile diameter $(d)$, we employ the sequential quadratic programming to optimize the object function to get the limit uplift capacity of single piles. This is an iterative method for nonlinear optimization and has become the most successful method for solving nonlinearly constrained optimization problems [9].

\section{Verification and Numerical Result}

4.1. Existing Predictive Models. In the following, the commonly applied predictive models are described in brief. Standard model method, the earliest method, assumed that the failure takes place on a cylindrical surface. Net uplift capacity of a vertical pile can be estimated as follows:

$$
P_{\mathrm{nu}}=\frac{1}{2} \pi K_{s} d \gamma L^{2} \tan \delta,
$$

where $K_{s}$ is the lateral earth pressure coefficient, $d$ is the diameter of the pile, $\gamma$ is the unit weight of the soil, $L$ is the length of the pile, and $d$ is the pile-soil friction angle. Levacher and Sieffert [10] and Das [11] suggested that $K_{s}$ can be taken as equal to $K_{0}=(1-\sin \varphi)$ for bored piles. Field engineers generally estimate the uplift capacity of the pile by assuming a slip surface as a truncated inverted cone with the enveloping sides rising at $\varphi / 2$ degrees from the vertical. Dead weight within the frustum is usually considered as the ultimate uplift capacity of the pile. Consider

$$
P_{\mathrm{nu}}=\frac{1}{3} \pi \gamma L^{3} \tan ^{2} \frac{\varphi}{2} .
$$

Meyerhof's model method [12] ignored the weight of the pile. The uplift capacity can be expressed as

$$
P_{\mathrm{nu}}=\frac{1}{3} \pi K_{u} d \gamma L^{2} \tan \delta,
$$

where $K_{u}$ is the uplift coefficient and can vary within wide limits and can depend not only on the soil properties, but also on the type of pile and method of installation. Das [13] reported that the unit skin friction at the soil pile interface increases linearly with depth up to a critical embedment ratio. The critical embedment ratio is dependent on the relative density $\left(D_{r}\right)$ and is expressed as

$$
\begin{gathered}
\left(\frac{H}{d}\right)_{\mathrm{cr}}=0.156 D_{r}+3.58, \quad D_{r} \leq 0.7, \\
\left(\frac{H}{d}\right)_{\mathrm{cr}}=14.5, \quad D_{r} \geq 0.7 .
\end{gathered}
$$

Uplift capacity of piles in sand can be estimated as

$$
\begin{gathered}
P_{u}=\frac{1}{2} p \gamma \pi K_{u} L^{2} \tan \delta, \quad \frac{L}{d} \leq\left(\frac{L}{d}\right)_{\mathrm{cr}}, \\
P_{u}=\frac{1}{2} p \gamma \pi K_{u} L_{\mathrm{cr}}^{2} \tan \delta+p \gamma L_{\mathrm{cr}} K_{u} \tan \delta\left(L-L_{\mathrm{cr}}\right), \\
\frac{L}{d} \geq\left(\frac{L}{d}\right)_{\mathrm{cr}} .
\end{gathered}
$$

Chattopadhyay and Pise [14] assumed the failure surface to be curved and proposed a generalized theory to evaluate uplift resistance of a circular vertical pile embedded in sand. Consider

$$
P_{u}=A_{1} \pi d \gamma L^{2},
$$

where $A_{1}$ is the uplift capacity factor. The above theories differ mainly in their assumptions with regard to the shape and extent of the failure surface. 


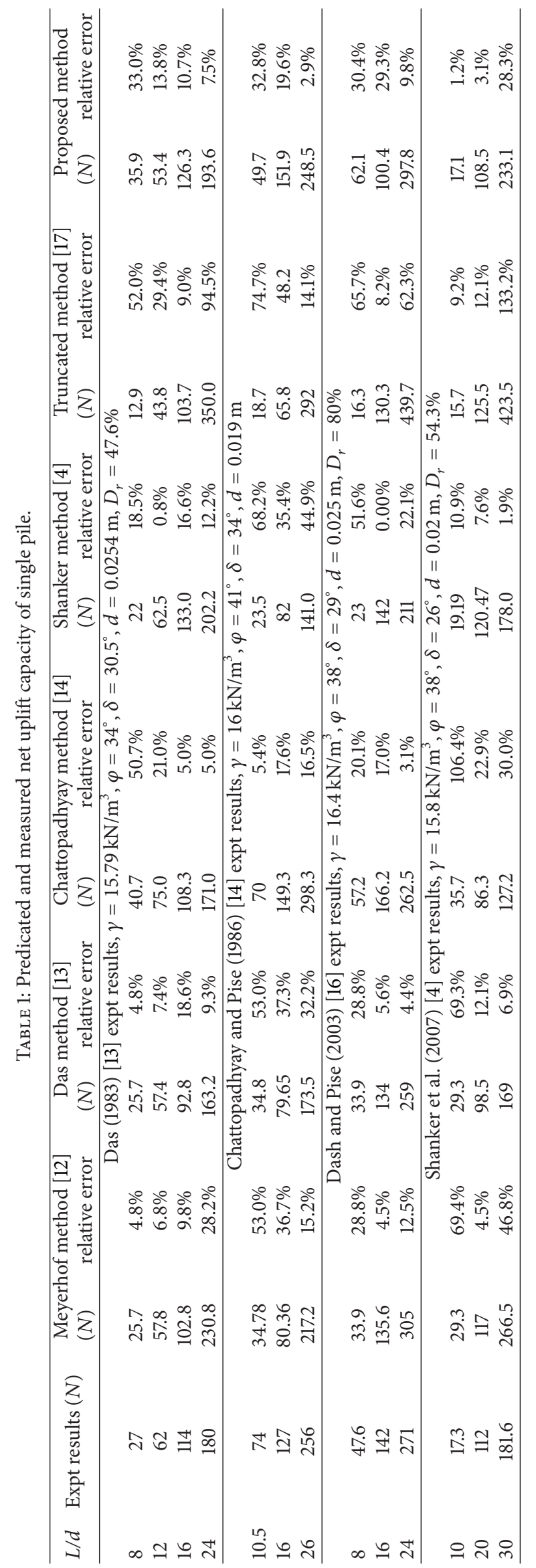


TABLE 2: Error between the proposed method and model experimental values of the ultimate uplift capacity.

\begin{tabular}{lcc}
\hline Method & $\begin{array}{c}\text { Maximum } \\
\text { relative error }\end{array}$ & $\begin{array}{c}\text { Average } \\
\text { relative error }\end{array}$ \\
\hline Meyerhof method & $69.4 \%$ & $21.6 \%$ \\
Das method & $69.3 \%$ & $17.7 \%$ \\
Chattopadhyay method & $106.4 \%$ & $15.6 \%$ \\
Shanker method & $51.6 \%$ & $22.1 \%$ \\
Truncated method & $133.2 \%$ & $51.7 \%$ \\
Proposed method & $33.0 \%$ & $14.8 \%$ \\
\hline
\end{tabular}

TABLE 3: Comparison of uplift capacity calculated using different methods and field test result.

\begin{tabular}{|c|c|c|c|}
\hline Parameters & & $\begin{array}{c}\text { Gross uplift capacity } \\
(\mathrm{kN})\end{array}$ & \\
\hline Diameter (m) & 1.2 & $\begin{array}{l}\text { Ismael and Klym } \\
\text { full-scale test }\end{array}$ & 888.8 \\
\hline Length (m) & 6.4 & $\begin{array}{l}\text { Chattopadhyay } \\
\text { method [14] }\end{array}$ & 968.8 \\
\hline Internal friction angle (Deg.) & 34 & Shanker method [4] & 714.3 \\
\hline Pile-soil friction angle (Deg.) & 27 & $\begin{array}{c}\text { Truncated method } \\
{[17]}\end{array}$ & 463.2 \\
\hline \multirow[t]{2}{*}{ Unit weight $\left(\mathrm{kN} / \mathrm{m}^{3}\right)$} & 11 & $\begin{array}{l}\text { Meyerhof method } \\
{[12]}\end{array}$ & 325.1 \\
\hline & & Proposed method & 935.2 \\
\hline
\end{tabular}

4.2. Comparisons with Different Methods. Values of proposed net uplift capacity have been compared with different predictive methods and model experimental results conducted by several scholars. As can be seen from Tables 1 and 2, the maximum relative error between the proposed method and model experimental values of the ultimate uplift capacity is within $33.0 \%$, and the average relative error is $14.8 \%$. However, the relative error of the Meyerhof method is within $69.4 \%$, and the average relative error is $21.6 \%$; the relative error of the Das method is within $69.3 \%$, and the average relative error is $17.7 \%$; the relative error of the Chattopadhyay method is within $106.4 \%$, and the average relative error is $15.6 \%$; the relative error of the Shanker method is within $51.6 \%$, and the average relative error is $22.1 \%$; the relative error of the Truncated method is within $133.2 \%$, and the average relative error is $51.7 \%$. From the above study it is found that the proposed method can give more reasonable predictions.

Ismael and Klym [15] reported a full-scale test under uplift of cylindrical pier of diameter $1.2 \mathrm{~m}$ and a length of $6.4 \mathrm{~m}$, embedded in a compact fine to medium sand with some silt and traces of clay. The internal friction angle equals $34^{\circ}$, and soil unit weight is $11 \mathrm{kN} / \mathrm{m}^{3}$. The pile-soil friction angle is $80 \%$ of the value of $\varphi$ for theoretical prediction [16]. The predicted gross uplift capacity is $935.2 \mathrm{kN}$, very close to the field test measured value of $888.8 \mathrm{kN}$. A comparison of the results obtained by different theoretical method is investigated in Table 3. It is seen that the predicted gross uplift capacity is in agreement with the values reported by Chattopadhyay and Pise [14] and Shanker et al. [4].

$$
\begin{array}{cc}
L / d=8 & n=16 \\
\varphi=20^{\circ} & \delta=\varphi / 2
\end{array}
$$

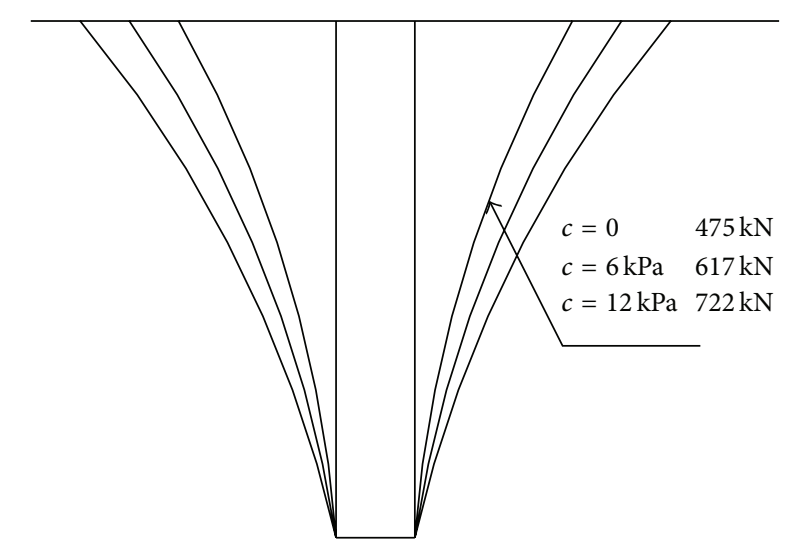

FIGURE 4: Failure surface shape and position with different internal friction angles.

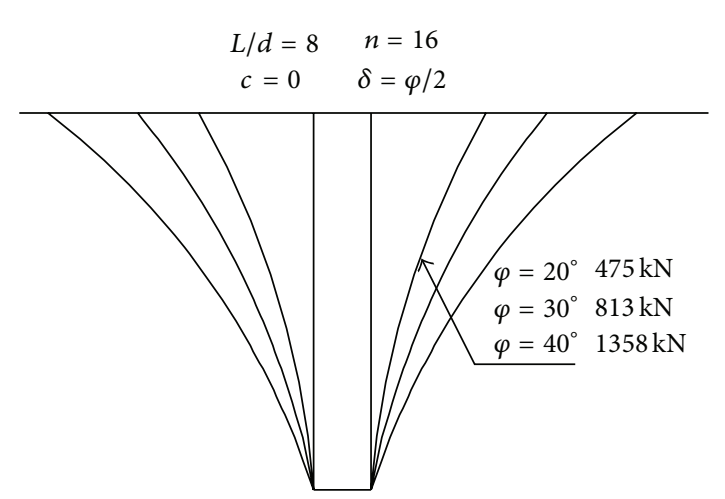

FIGURE 5: Failure surface shape and position with different cohesions.

Meanwhile, the results obtained by Meyerhof [12] method and Truncated [17] method underestimate the experimental results.

4.3. Failure Surface Comparison. The ultimate uplift capacity can be significantly influenced by the shape and position of failure surfaces. Figures 4 and 5 show the influence of the cohesion and internal friction angle on the shape and position of failure surfaces with $L / d=8, d=1 \mathrm{~m}, \gamma=15.79 \mathrm{kN} / \mathrm{m}^{3}$, and $n=16$. The results show that with the increase of the value of cohesion and internal friction angle, the ultimate uplift capacity can improve effectively. The failure surface moves to the pile gradually with decreasing cohesion and internal friction angle.

\section{Summary and Conclusions}

A theoretical method for predicting the uplift capacity and failure surface of piles embedded in $c-\varphi$ soil has been proposed based on the horizontal slice method in the framework of limit equilibrium analysis. The relation among the ultimate 
uplift capacity, the failure surface position, and soil parameters was discussed. It enables a reasonably logical analysis and the quantitative estimates to be made of the effects of soil parameters. The results obtained by the proposed method are found to be in close agreement with model experimental and full-scale test results. With the increase of the value of cohesion and internal friction angle, the ultimate uplift capacity can improve effectively. The failure surface moves to the pile gradually with decreasing cohesion and internal friction angle.

\section{Conflict of Interests}

The authors declare that there is no conflict of interests regarding the publication of this paper.

\section{References}

[1] V. B. Deshmukh, D. M. Dewaikar, and D. Choudhury, "Computations of uplift capacity of pile anchors in cohesionless soil," Acta Geotechnica, vol. 5, no. 2, pp. 87-94, 2010.

[2] A. Shelke and N. R. Patra, "Effect of arching on uplift capacity of single piles," Geotechnical and Geological Engineering, vol. 27, no. 3, pp. 365-377, 2009.

[3] A. Shelke and S. Mishra, "Uplift capacity of single bent pile and pile group considering arching effects in sand," Geotechnical and Geological Engineering, vol. 28, no. 4, pp. 337-347, 2010.

[4] K. Shanker, P. K. Basudhar, and N. R. Patra, "Uplift capacity of single piles: predictions and performance," Geotechnical and Geological Engineering, vol. 25, no. 2, pp. 151-161, 2007.

[5] D. Mohan and S. Chandra, "Frictional resistance of bored piles in expansive clays," Geotechnique, vol. 11, no. 4, pp. 294-301, 1961.

[6] E. Z. Turner, "Uplift resistance of transmission tower footings," Journal of the Power Division, ASCE, vol. 88, no. 2, pp. 17-34, 1962.

[7] V. A. Sowa, "Pulling capacity of concrete cast in situ bored piles," Canadian Geotechnical Journal, vol. 7, no. 4, pp. 482-493, 1970.

[8] E. C. Shin, B. M. Das, V. K. Puri, S. C. Yen, and E. E. Cook, "Ultimate uplift capacity of model rigid metal piles in clay," Geotechnical and Geological Engineering, vol. 11, no. 3, pp. 203215, 1993.

[9] P. T. Boggs and J. W. Tolle, "Sequential quadratic programming," Acta Numerica, vol. 4, pp. 1-51, 1995.

[10] D. R. Levacher and J. Sieffert, "Tests on model tension piles," Journal of Geotechnical Engineering, vol. 110, no. 12, pp. 17351748, 1984.

[11] B. Das, Principles of Foundation Engineering, Cengage Learning, Stamford, Conn, USA, 2010.

[12] G. G. Meyerhof, "The uplift capacity of foundations under oblique loads," Canadian Geotechnical Journal, vol. 10, no. 1, pp. 64-70, 1973.

[13] B. M. Das, "A procedure for estimation of uplift capacity of rough piles," Soils and Foundations, vol. 23, no. 3, pp. 122-126, 1983.

[14] B. C. Chattopadhyay and P. J. Pise, "Uplift capacity of piles in sand," Journal of Geotechnical Engineering, vol. 112, no. 9, pp. 888-904, 1986.

[15] N. F. Ismael and T. W. Klym, "Uplift and bearing capacity of short piers in sand," Journal of the Geotechnical Engineering Division, vol. 105, no. 5, pp. 579-594, 1979.
[16] B. K. Dash and P. J. Pise, "Effect of compressive load on uplift capacity of model piles," Journal of Geotechnical and Geoenvironmental Engineering, vol. 129, no. 11, pp. 987-992, 2003.

[17] G. G. Meyerhof and J. I. Adams, "The ultimate uplift capacity of foundations," Canadian Geotechnical Journal, vol. 5, no. 4, pp. 225-244, 1968. 


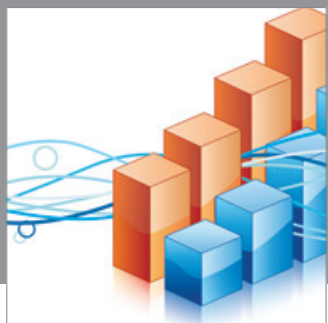

Advances in

Operations Research

mansans

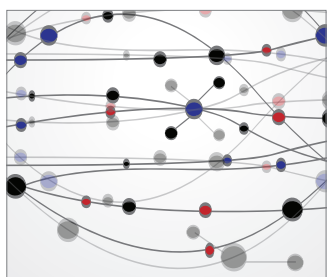

The Scientific World Journal
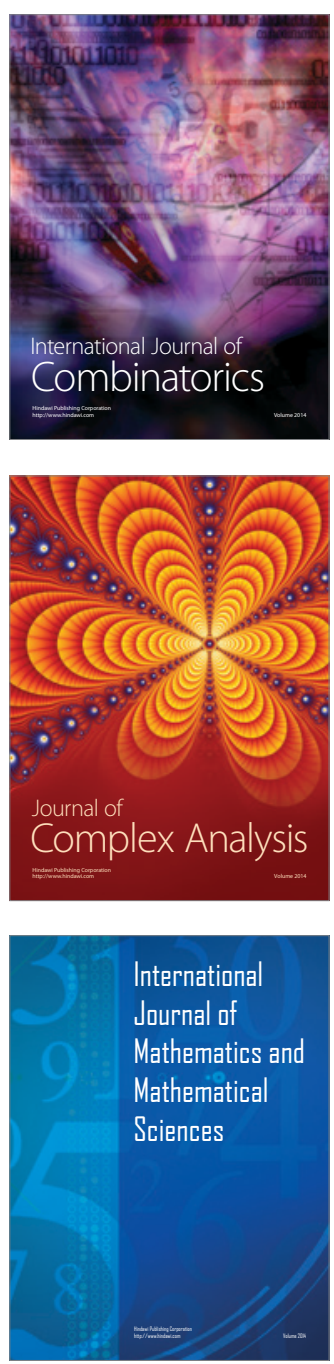
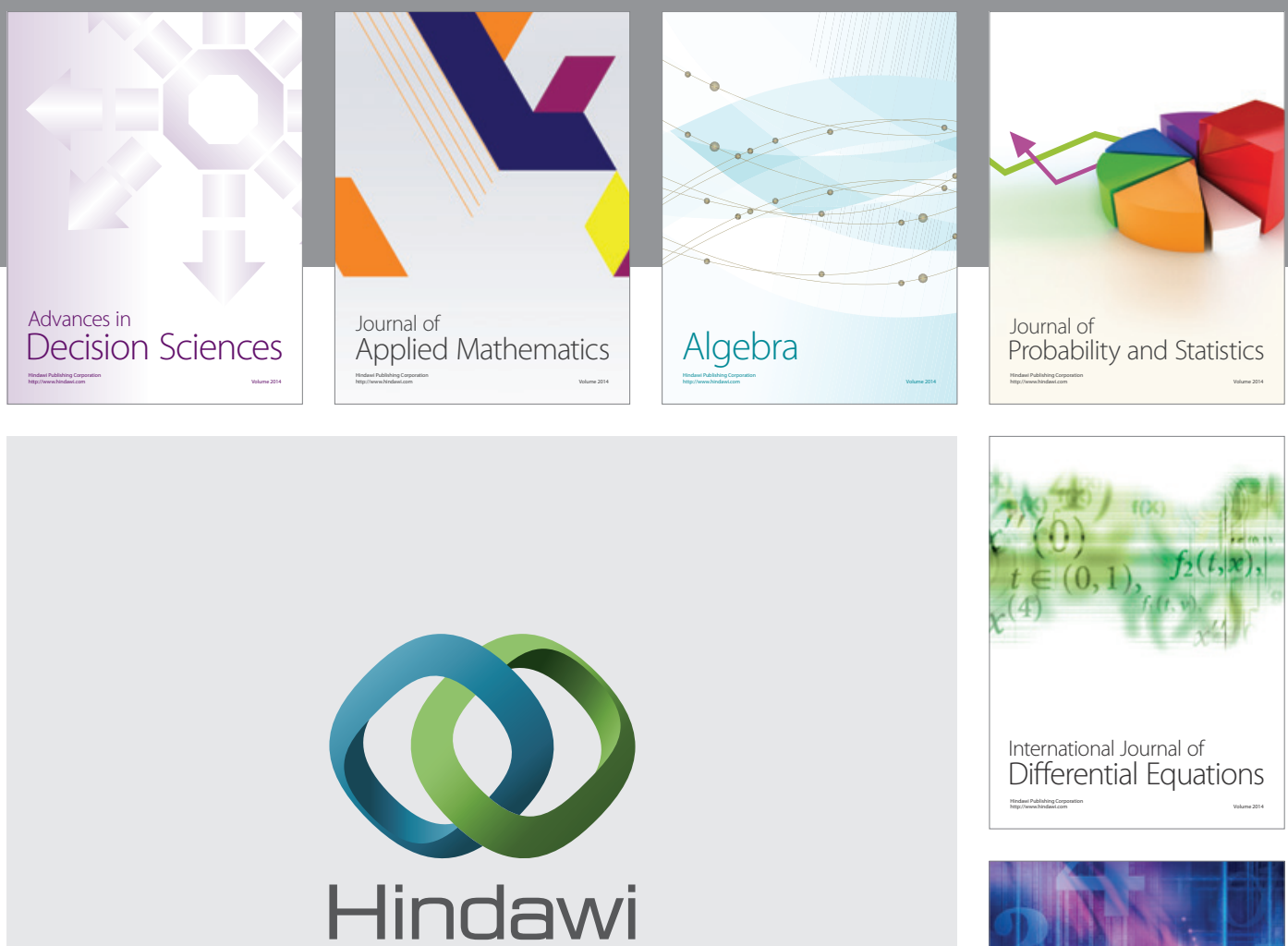

Submit your manuscripts at http://www.hindawi.com
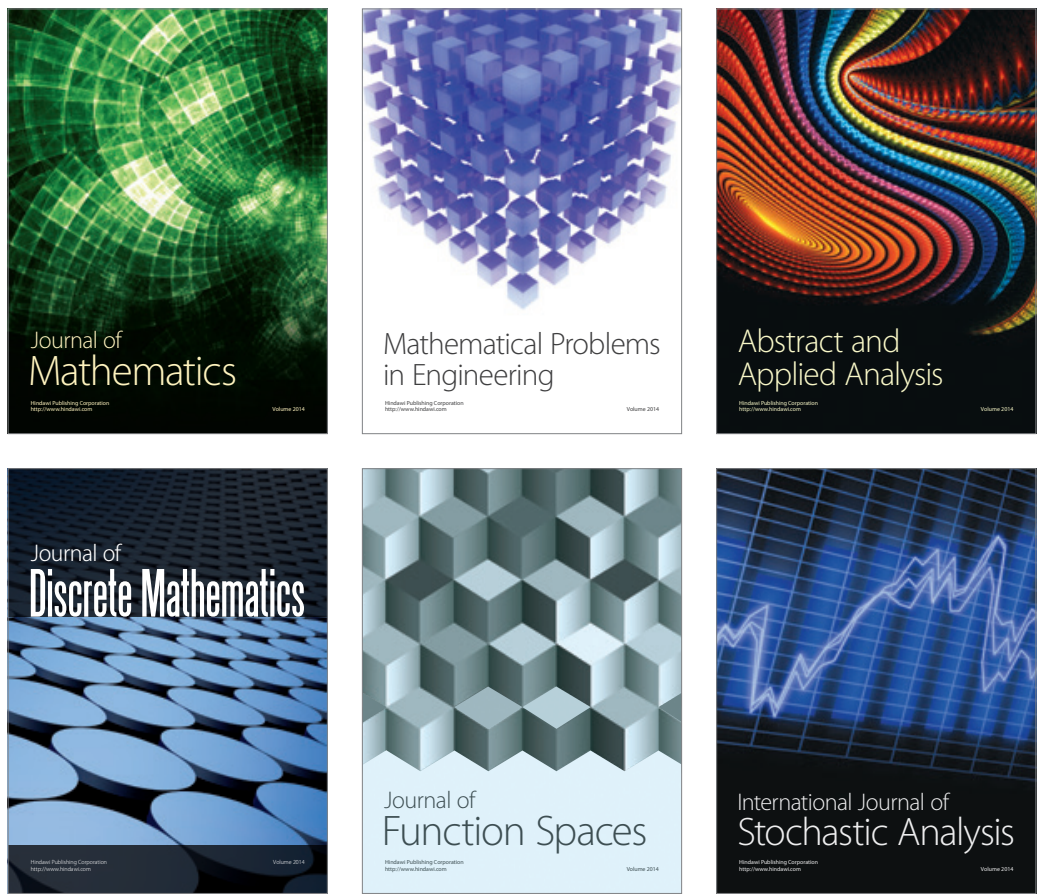

Journal of

Function Spaces

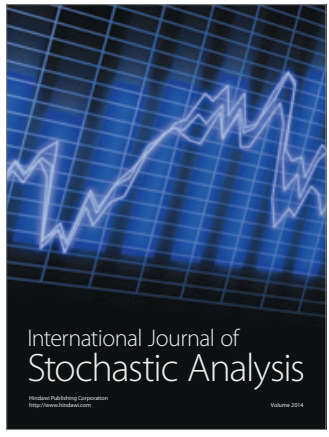

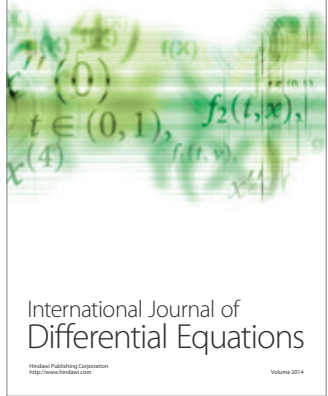
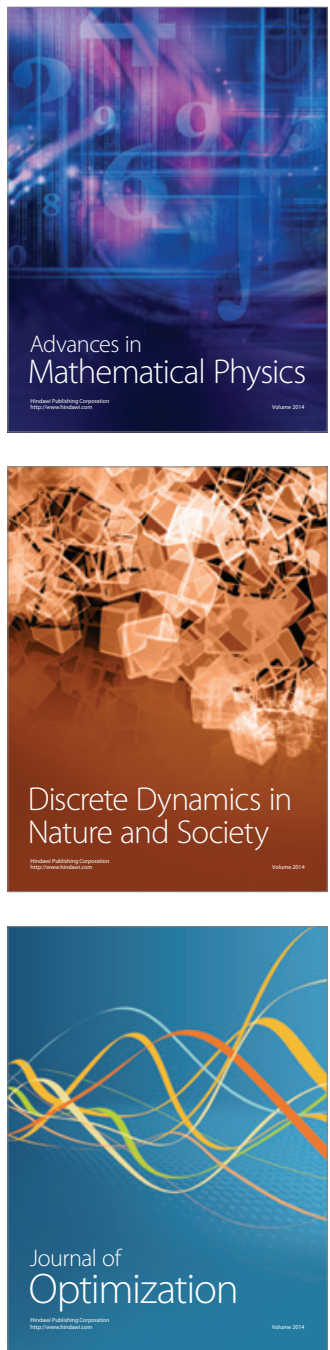